\title{
Novel lineage of a green alga and Acremonium stroudii (Ascomycota) sp. nov. reported from Ascension Island
}

\author{
K.I.G. FLETCHER ${ }^{1,2}$, J. SIM $^{3}$, N. WILLIAMS ${ }^{3}$, N. WEBER ${ }^{3}$, F.C. KÜPPER ${ }^{2}$ AND P. VAN WEST ${ }^{1}$ \\ ${ }^{1}$ Aberdeen Oomycete Laboratory, Institute of Medical Sciences, University of Aberdeen, Foresterhill, Aberdeen, AB25 2ZD, \\ Scotland, UK, ${ }^{2}$ Oceanlab, University of Aberdeen, Newburgh, Ellon, Aberdeenshire, AB41 6AA, Scotland, UK, ${ }^{3}$ Ascension Island \\ Government Conservation Department, Georgetown, Ascension Island, South Atlantic Ocean, ASCN 1ZZ
}

\begin{abstract}
Environmental specimens lining seawater blowholes of Whale Point, Ascension Island in the South Atlantic Ocean were collected (August 2012) and investigated by morphological and molecular techniques. Reported here, Acremonium stroudii (Ascomycota) sp. nov., a filamentous conidia-forming fungus, was the only fungus isolated from the samples collected. Molecular analysis of the material also indicates the presence of a novel species of green algae being present, however, isolation of this alga has not been possible. Instead it appears that this specimen, which belongs to a novel lineage within the Ulvales, sister to the Dilabifilum species, encourages fungal growth in culture and has been shown to form a symbiotic relationship on low nutrition agar plates, supported by investigation through electron microscopy. As no holotype of this species could be isolated in an axenic culture it was not suitable at this point to try to define this alga, especially as no established genus could be attributed. We recommend trying to further sample areas of Ascension Island looking for other members of this green algal lineage, both investigating free-living green algae and those which are found as lichenized photobionts.
\end{abstract}

Keywords: Pirula, environmental sample, SSUrRNA, ITS, phylogenetics, electron microscopy, Dilabifilum, lichen, symbiosis

Submitted 24 June 2015; accepted 7 July 2015; first published online 21 September 2015

\section{INTRDDUCTION}

Ascension Island is geologically a relatively young volcanic island, located in the central South Atlantic Ocean $\left(7.9333^{\circ} \mathrm{S}\right.$ $14.3667^{\circ} \mathrm{W}$ ), with a unique natural history, which has been heavily impacted by the activities of man (Catling \& Stroud, 2015). Discovered in 1501, the island was often remarked as being barren with the apparent absence of fresh water (Mundy et al., 1907) making the island of little interest to passing sailors, until the 18th and 19th century, when traders would often source green turtles (Ascension Island being the nesting site for these animals) as a regular supply of food (Catling \& Stroud, 2015). From the early 19th century Ascension Island became populated by man, beginning the massive alteration of the terrestrial ecosystem chiefly due to the introduction of non-native species which has led to the transformed environment, visible especially upon the highest peak, Green Mountain, today (Brown, 1877; Fairhurst, 2004; Catling \& Stroud, 2015). The lower ranges of Ascension remain largely a dry volcanic desert, with mesquite (Mexican thorn, Prosopis juliflora), an invasive plant species from the deserts of SW North America dominating much of these areas of the island and constituting a problem for native biota (Belton, 2008). Other geographic features of Ascension Island include two freshwater springs;

Corresponding author:

P. van West

Email: p.vanwest@abdn.ac.uk
Dampier's Drip on the north-east side of green mountain and Breakneck Valley to the south-east of Green Mountain. The latter was thought to have been discovered in the 18th century, due to the sinking of the HMS Roebuck and is now blocked with concrete to allow the retention of water (McCarthy \& George, 2002; Catling \& Stroud, 2015). Of focus in this study, Whale Point is located on the east of Ascension Island; here seawater vents can be found to run from presumed sea caves under the volcanic rock of the shore.

Many species inventories from Ascension Island are currently lacking, with the development of these being a key aim of the Darwin Initiative SMSG Challenge Award. Lichens, of potential relevance to this study have recently been catalogued from Ascension Island, though Whale Point was not used as a sampling location (Aptroot, 2008; Aptroot et al., 2012). Briefly a lichen is defined as a stable symbiotic association of a fungus (mycobiont) which forms an encasement (thallus) around a photosynthetic partner (photobiont), typically an alga or cyanobacterium and may involve the production of fungal haustoria, which penetrate the algal tissue allowing the fungus to live off the alga (Ahmadjian, 1993). Mycophycobiosis is an alternative symbiosis, where the fungus is entirely encased within the algal thallus in a symbiotic relationship and is regarded as entirely different from a lichen symbiosis (Kohlmeyer \& Kohlmeyer, 1972). Both of these interactions should not be confused with parasitism, where the alga is detrimentally affected by an infectious fungal agent, or saprophytism, where an additional organism may survive on another organism which is dead or decaying. For example, lichenicolous fungi are a highly specialized group of organisms, which grow, often inconspicuously, parasitically 
upon a live lichen thallus or saprotrophically upon a dead organism (Diederich, 2003; Lawrey \& Diederich, 2003).

This study aims to identify and characterize the constituents of green crustose environmental material collected from the seawater blow holes of Whale Point, Ascension Island and reveal the phylogenetic affinities of the specimens isolated from this material using morphological and molecular techniques.

\section{MATERIALS AND METHDDS}

\section{Collection}

Two narrow seawater blowholes located at Whale Point, Ascension Island $\left(7.95^{\circ} \mathrm{S} 14.3^{\circ} \mathrm{W}\right)$, both at least $20 \mathrm{~m}$ deep, were sampled. A pole, with hand shovel attached, was used to reach and collect samples from within the blowholes. Large rocks once displaced were inspected for signs of living material. Samples, once collected, were placed into sterile dry tubes and sealed with parafilm, before being shipped to the University of Aberdeen.

\section{Culturing}

The collected material was removed delicately from attached substrate and washed three times with distilled water. These specimens were then placed on/in high nutritional media; Potato Dextrose Agar (PDA; SigmaAldrich: 70139) and Oatmeal Agar (OA) plates, marine media; Provasoli Enriched Seawater (PES; Provasoli, 1968; Bold \& Wynne, 1985), liquid and $1 \%$ agar plates and lower nutritional media; Bold's Basal Media (BBM; Bischoff \& Bold, 1963; Starr \& Zeikus, 1993), ES and MGM (Ichimura, 1973) again, both as liquid media and $1 \%$ agar plates. In parallel, the washed material was macerated and mechanically disrupted in a small volume of sterile distilled water. These were then diluted in a $10 \times$ serial dilution $1 \mathrm{X}-1 \times 10^{-9}$ and these suspensions were spread on the plates outlined above. Plates were then stored in a light chamber, simulating daylight with $12 \mathrm{~h}$ cycles at $12,15 \& 20^{\circ} \mathrm{C}$. Plates and liquid cultures were observed daily by eye or using a Zeiss PrimoVert inverted microscope, in instances of fungal growth, mycelia were cut out of the plate and placed onto fresh media to proliferate the culture. These second generation cultures were then used for molecular investigation. In cases where green algae were large enough to be viewed under a dissection microscope it would be removed from the culture and used to initiate new cultures.

Mixed cultures, where a green alga constituted the majority of the biomass, but could not be isolated from fungal mycelia, were mechanically disrupted again, and used in a $10 \times$ serial dilution series, as above. These dilutions were then used to initiate fresh cultures. In parallel these mixed cultures were also used for phylogenetic investigation (see below for further details). Other methods employed to separate the alga in such situations included spreading of macerated and mechanically disrupted suspensions on nutritionally depleted agar plates (i.e. BBM, ES) and placed in incubators of varying temperatures $\left(5,9,12\right.$ and $\left.20^{\circ} \mathrm{C}\right)$. The cultures were also spread on a range of $\mathrm{pH}$-variable $\mathrm{BBM}$ plates $\left(\mathrm{pH}_{3}-9\right.$, with one incremental $\mathrm{pH}$ unit) to try to discourage fungal growth. Finally mechanical separation through density centrifugation (Fontaniella et al., 2000) was also employed. Green colonies, which appeared non- axenic (i.e. with clear fungal mycelia present) were left to propagate on plates while any isolated algae would be placed into liquid media (BBM/PES). Isolated algae were used for further morphological and molecular investigation, while the thalli formed on plates were investigated further by light and electron microscopy and chemical tests.

\section{Microscopy}

Colonies growing on BBM ( $1 \%$ agar) in a Petri dish were imaged using Nikon D8ooe with $60 \mathrm{~mm}$ AF-S F2.8G Micro Nikkor lens by opening the plate in a sterile environment (i.e. laminar flow cabinet). Dissection microscopic images were produced by taking a fragment and washing it $3 \times$ in sterile distilled water and placing it on a Petri dish. The thallus was then manipulated and sectioned using sterile dissection needles and scalpel. Images were taken down the lens of the dissection microscope using the camera of an iPhone $4 \mathrm{~S}$ (8 megapixels).

Sections produced under the dissection microscope were placed on to a microscope slide with a drop of water and a cover slip was applied. These were then imaged using a ZEISS Axio imager D2 inverted microscope with ZEISS Axiocam MRC. Sections were also placed into a drop of 85\% lactic acid (SigmaAldrich: 69775) and then stained with lactophenol blue (SigmaAldrich: 61335; Perdomo et al., 2011) to try to discern fungal material from algal material. Finally whole thalli and sections were fixed using $2.5 \%$ glutaraldehyde in $0.1 \mathrm{M}$ phosphate buffer ( $\mathrm{pH}$ 7.2). For scanning electron microscopy the samples were washed three times using $0.1 \mathrm{M}$ phosphate buffer ( $\mathrm{pH}$ 7.2) and then dehydrated in an ethanol series to $100 \%$. HMDS (hexamethylisilazane) was then added to dry material and left overnight. The material was then mounted on studs, sprayed with gold particles and viewed using a Zeiss ECO MA10 SEM. For transmission electron microscopy the fixed material was washed with $0.1 \mathrm{M}$ phosphate buffer $(\mathrm{pH} 7.2) 3 \times$ and post fixed with $\mathrm{OsO}_{4}$, before further washing with distilled water $(3 \times)$ and dehydration through an ethanol series $(30 \%, 70 \%, 95 \%)$ followed by 3 washes with $100 \%$ acetone. Spurr's resin was then infiltrated into the material through incubation of the specimens in a series of differing ratios with acetone (Acetone:Spurr's: 7:1, $3: 1,1: 1,1: 3,1: 6)$ until finally being incubated in $100 \%$ Spurr's resin and polymerized at $60-70^{\circ} \mathrm{C}$. Samples were then sectioned using an ultramicrotome and placed on copper grids before being contrast stained with lead citrate and uranyl acetate. Sections were imaged using a JEM- 1400 Plus (JEOL) TEM with an AMT UltraVue camera.

\section{Molecular methods}

DNA was extracted from pure fungal cultures and mixed fungal/algal cultures using an optimized CTAB protocol (Gachon et al., 2009), quantified using a spectrophotometer $(230 / 260 \mathrm{~nm})$ and diluted to suitable concentrations for PCR. Both sets of samples were used in reactions to amplify the ITS region, ITS 1 and ITS 4 (White et al., 1990) with cycling conditions of $95^{\circ} \mathrm{C} \times 5 \mathrm{~min}, 35 \times\left(95^{\circ} \mathrm{C} \times 30 \mathrm{~s}, 55^{\circ} \mathrm{C} \times 30 \mathrm{~s}\right.$, $\left.72^{\circ} \mathrm{C} \times 45 \mathrm{~s}\right), 72^{\circ} \mathrm{C} \times 5 \mathrm{~min}$ using $5.0 \mathrm{mM} \mathrm{MgCl}_{2}$ and SSU rRNA NS1xNS4 (White et al., 1990) with cycling conditions $95^{\circ} \mathrm{C} \times 5 \mathrm{~min}, \quad 35 \times\left(95^{\circ} \mathrm{C} \times 30 \mathrm{~s}, \quad 55^{\circ} \mathrm{C} \times 30 \mathrm{~s}, \quad 72^{\circ} \mathrm{C} \times\right.$ $1 \mathrm{~min}), 72^{\circ} \mathrm{C} \times 5 \mathrm{~min}$ with $4.0 \mathrm{mM} \mathrm{MgCl}_{2}$ using FlexiTaq (Promega; M7805). PCR products were then purified using 
the GeneJet ${ }^{\mathrm{TM}}$ nucleic acid purification kit (ThermoScientific; Ko701) and Sanger sequenced using the primers outlined above by Eurofins sequencing service.

Returned ABI files were analysed for quality and trimmed by viewing the chromatograms in BioEdit (Hall, 1999), to produce a single consensus sequence. BLASTn was used to determine where the sequence is likely to branch and suitable multiple sequence alignments (MSA) were constructed based on these results. Maximum likelihood tests of phylogeny were performed with MEGA 6.05 (Tamura et al., 2013), using the Tamura-Nei model and a Nearest Neighbour Interchange heuristic method. Gaps/missing data were treated as a partial deletion if the site coverage cut off was over $95 \%$ and 1000 bootstraps were used as a test of phylogeny. Accession numbers used for the MSA and test of phylogeny can be found in the final phylogram. Sequences were deposited in GenBank under accessions KM225291 and KM225292 and MSA files provided as supplementary materials.

\section{RESULTS}

\section{Fungal isolation}

A fungus was easily isolated and could be grown away from the material by directly placing the specimen on PDA or OA agar plates. Light microscopy of material isolated from PDA plates allowed investigation of the internal mat, where conidia (asexual, non-motile spores), measured to approximately $2.5-3.0 \mu \mathrm{m}$ in diameter, could clearly be discerned from the mycelia of the fungi (Figure $1 \mathrm{~A}$ ). Staining material from the periphery of the mat with lactophenol blue (Figure $1 \mathrm{~B}$ ) allowed further observation of conidia which appeared to not be contained within slimy capsules. Conidia here were measured to be between $1.0-2.0 \mu \mathrm{m}$ in diameter, and hyphae were less than $1.0 \mu \mathrm{m}$ wide. This fungus was deposited at CBS under accession CBS 138820.

\section{Algal isolation}

\section{LIQUID MEDIA}

A single unicellular green alga was observed from the environmental material, however isolation of this organism was not possible in the present study. The method which came closest to successfully isolating the alga involved mechanical disruption of the material, followed by dilution and initiating liquid PES cultures. Often the $100 \times$ dilution would appear to have small green multi-cellular tufts (Figure 2A, B), of circular/oval (coccoid) cells which would then project longer thin cells away from this central body (Figure $2 \mathrm{~B}-\mathrm{F}$ ), however both in cultures where these tufts were isolated and re-cultured and in cultures which were left untouched a large mycelia network developed, formed from a separate fungus from that isolated above (Figure $2 \mathrm{G}-\mathrm{H}$ ). It is apparent that the mycelia may have begun forming when associated with an alga in some instances (Figure $2 \mathrm{G}$ ). The green algal tufts soon became incorporated within these mycelia, however it did not seem to cause the death of these cells, indeed the green alga appeared to continue its existence while associated with this network for the course of this study. No other algal cultures which were maintained within the lab suffered a similar fate, suggesting that this was not an issue of contamination.

Increased exposure to light was found to be detrimental to the green alga, becoming over-run by the fungus and eventually dying. It is unknown if this was caused directly by the fungus or if the high light levels had a detrimental effect on the alga.

\section{SOLID MEDIA}

Dark green circular colonies occurred on the plates spread with deionized water used to macerate a section of the algal thallus, but these were always found to be non-axenic (i.e. containing a fungal symbiont with the desired green algae) when analysed through a dissection microscope (Figure 3). Thalli become lighter toward the extremities and investigating sections showed a segregation of material (Figure 3); the upper layer (within the thallus) could be seen to contain predominantly rounded algal cells, while the lower sections (exterior of the thallus) were seen to contain more hyphal cells of a fungus.

Cultivation on $\mathrm{pH}$ variable plates was unsuccessful in producing any growth of either fungal or algal origin and mechanical separation through density centrifugation of both the thallus and the mycobiont reduced culture (obtained through culturing in liquid PES, above) also failed to isolate the green alga. Green colonies were successful in growing
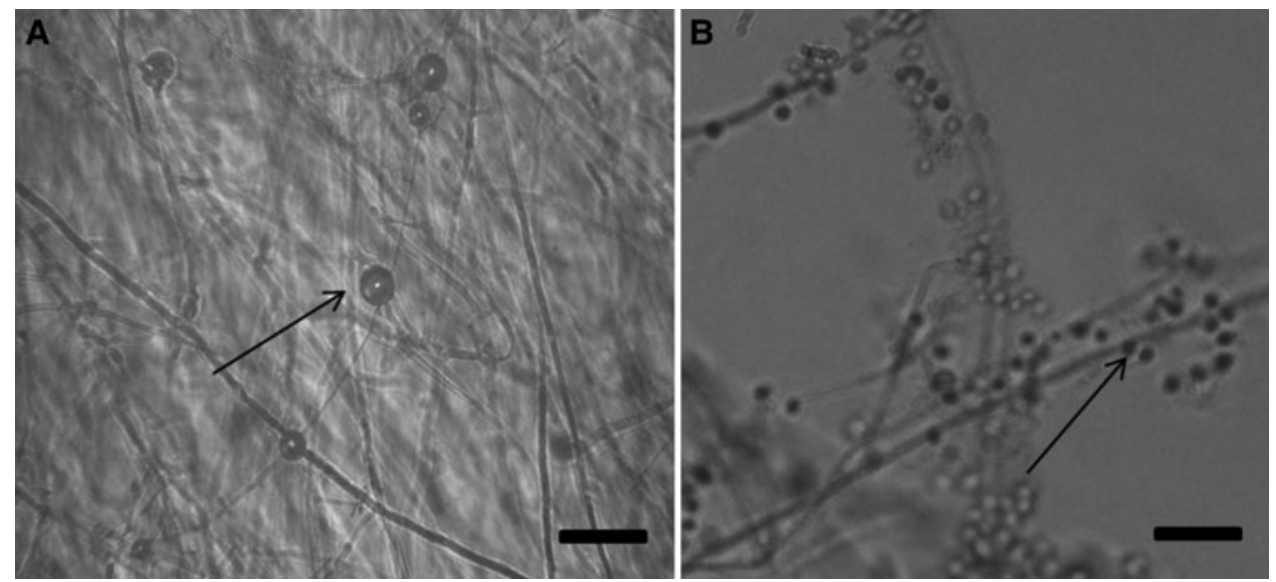

Fig. 1. Acremonium stroudii viewed under a light microscope. (A) An unstained and (B) lactophenol blue stained sample of the fungus. Conidia are indicated with arrows. Scale bar A, B, $10 \mu \mathrm{m}$. 

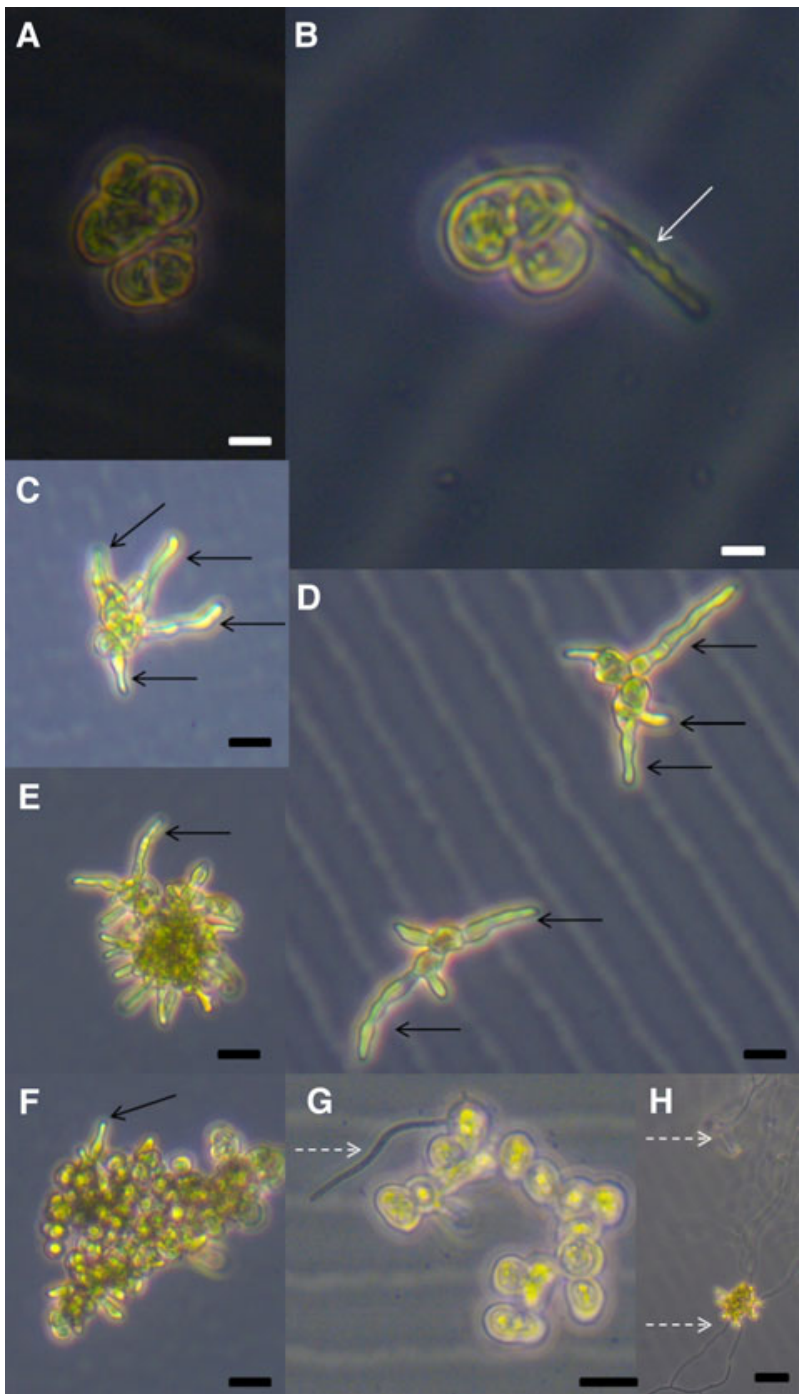

Fig. 2. Observations of early algal isolation attempts, through mechanical disruption. (A) Multiple spherical/oval algal cells in a cluster. (B) Severa algal cells with a filamentous cell (arrow) of unknown origin, likely algal. (C, D) Longer filamentous cells (arrow) growing out of clusters of algal cells. (E, F) Larger clusters of algal cells with filamentous cells (arrow). (G) Funga mycelium (arrowed) originating from the algal cluster. $(\mathrm{H})$ Late stage culture where algal clusters become incorporated in a mycelial mat (arrows). A-D \& $\mathrm{G}$ were imaged from BBM cultures, $\mathrm{E}, \mathrm{F} \& \mathrm{H}$ were imaged from PES cultures. Scale bars A, B, $10 \mu \mathrm{m} ; \mathrm{C}-\mathrm{G}, 20 \mu \mathrm{m} ; \mathrm{H}, 50 \mu \mathrm{m}$.

upon the plates, but in every instance the colony was shown to be surrounded by mycelia (i.e. Figure 3).

\section{Electron microscopy}

SEM investigation of the whole thallus (Figure $4 \mathrm{~A}, \mathrm{~B}$ ) mounted on a stud shows a remarkable matrix of fungal hyphae coating the thallus, with the back scatter images used to contrast the top layer (Figure $4 \mathrm{~B}$ ). As the thallus was observed at higher magnification levels (Figure $4 \mathrm{C}, \mathrm{D}$ ) no algal cells were noted, instead the hyphae appear to form a solid barrier constructed of hyphal material, possibly similar to a sclerotium, a compact mass of hardened fungal mycelia (Figure 4 C; Perdomo et al., 2011). Viewing pre-cut sections of the thallus (Figure $4 \mathrm{E}, \mathrm{F}$ ) allowed the exploration of the internal cells. Here coccoid algal cells could be seen, measured to be $8-10 \mu \mathrm{m}$ high $\times 4-6 \mu \mathrm{m}$ wide, in different states. Firstly healthy algal cells are seen to have smooth surfaces, with no fungal interaction, this is seen in the majority of cases (Figure $4 \mathrm{E}$ ). However some occurrences of likely moribund algal cells indicate an interaction of the two symbionts, with fungal mycelia running along the algal cells (Figure $4 \mathrm{~F}$ ). The algal cells themselves appeared to present a more abrasive exterior, possibly as some form of resistance, or as a sign of poor health (Figure $4 \mathrm{~F}$ ). No conidia were seen during analysis with SEM.

Investigation by TEM allowed ultra-morphological analysis of the photobiont contained within the specimen. It was seen that there was no direct interaction between algal cells, however being in close proximity to one another they were on occasion seen to conform to a compressed shape (Figure $5 \mathrm{~B}$ ). A longitudinal section of a typical photobiont cell from this specimen can be seen (Figure $5 \mathrm{~A}$ ), as found regularly in other instances within the material, the nucleus appears to be encased by a much larger, single chloroplast. Between the nucleus and the chloroplast in this instance another set of membranes can be viewed, thought to be the mitochondria, however as no internal cristae structures can be delimited it is not possible to say this with entire certainty. No other such structures can be seen within the cell. This arrangement of a nucleus, encased by a chloroplast was found to be common, yet it was not a uniform arrangement, occasionally the nucleus was positioned independently of the chloroplast.

No pathogenic structures (i.e. haustoria) were observed to invade an algal cell, though commonly the fungal cell was seen in close proximity to the algal cells (Figure $5 \mathrm{C}$ ), as was also noted through SEM (Figure 4). In one instance (Figure ${ }_{5} \mathrm{~F}$ ) the fungal cell can be seen to extend and expand around an algal cell, though still no pathogenic structures were observed. No apparent changes to the algal cell wall were noted in these circumstances. Fungal cells interacting with algal cells were seen to have dense micro-particles (Figure $5 \mathrm{C}-\mathrm{F}$ ) within the cytoplasm. It can be hypothesized that these structures play a role in the interaction between the two symbionts, though their role is at present unknown. There does not appear to be any gradation of these particles towards or away from the cell wall contact area of the photobiont. Similar particles, though not necessarily the same, are seen to be much smaller in the conidia of the mycobiont (Figure $5 \mathrm{D}, \mathrm{E}$ ).

\section{Phylogenetics}

$538 \mathrm{bp}$ of the fungal SSU rRNA, 5.8S rRNA, LSU rRNA and ITS complex was obtained [KM225291] giving a top blast result of Acremonium charticola ([AJ621774]; QC-92\%, Id-94\%, E-v-0.o). This sequence was therefore placed into a phylogeny of Acremonium sp. similar to those previously produced (i.e. Summerbell et al., 2011). The maximum likelihood topology (Figure 6) branches our specimen outside of a clade containing A. charticola (99/100) and two environmental sequences and sister to a separate clade containing another A. charticola sequence with two other environmental samples. $965 \mathrm{bp}$ of the green algal SSU $r R N A$ was successfully sequenced [KM 225292], the top blast hit were freshwater green algae (Pirula salina [AF124337], Chlorella emersonii [FR865654] and Dilabifilum sp. [JN573882], all equal; QC-98\%, Id-93\%, E-v-0.o). The sequence was therefore placed among an alignment containing multiple Ulvophyceae. 

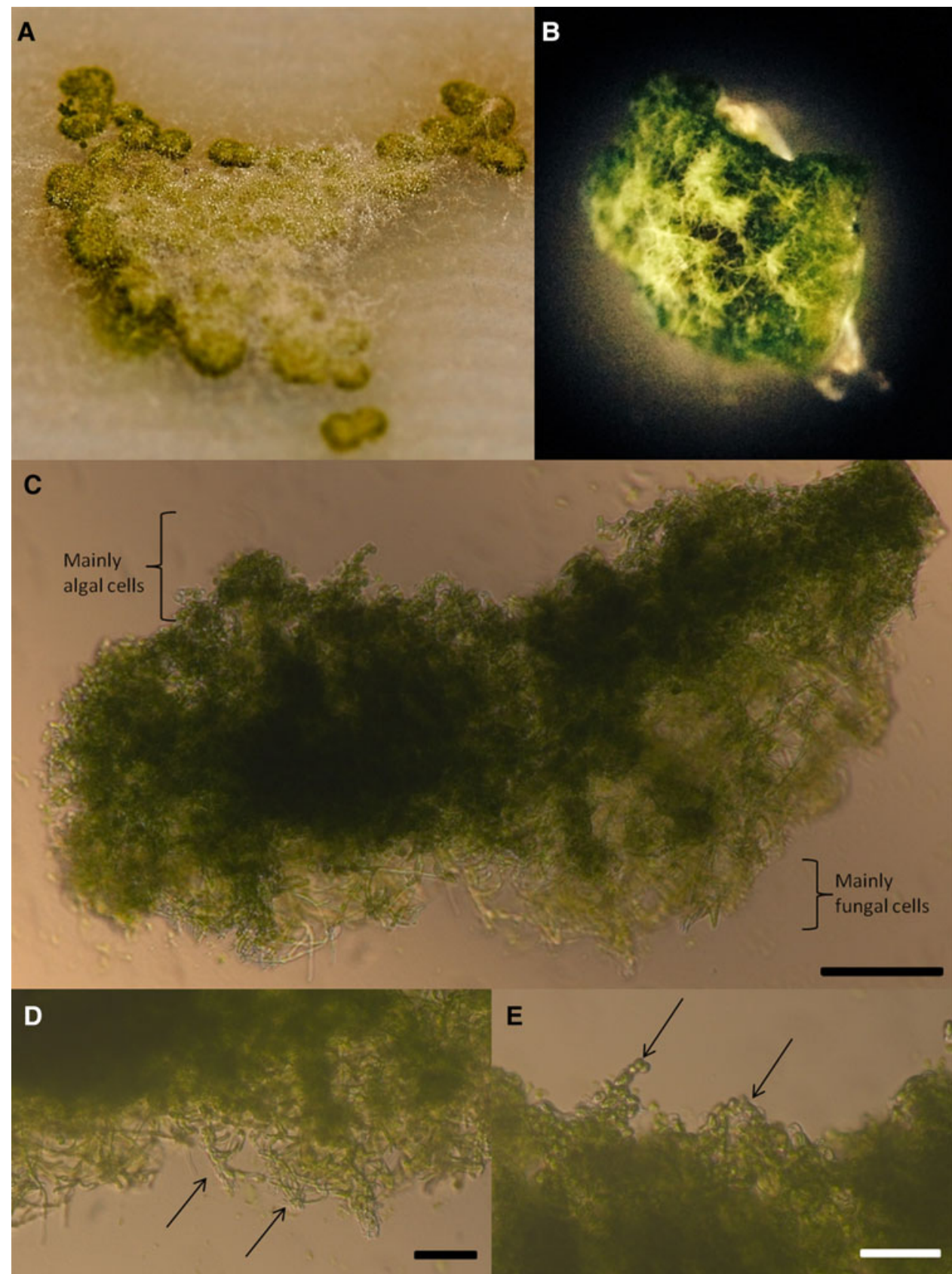

Fig. 3. Mycophyco thallus produced in attempted isolations of the green alga, on Bold's basal media. (A, B) the whole thallus, (C-E) sections of a thallus, (D) mainly fungal cells, (E) mainly algal cells. Scale bars A, $100 \mu \mathrm{m} ; \mathrm{B}, \mathrm{C}, 50 \mu \mathrm{m}$.

The maximum likelihood phylogeny produced (Figure 7) reveals a complication in the results as Chlorella emersonii, a Chlorellaceae, appears to branch within the Ulvophyceae; this placement is unaffected by the inclusion/exclusion of the recently obtained sequence and excluding the C. emersonii taxa from the phylogeny has no effect on the overall topology (data not shown). We therefore regard this as either a misidentification of a species or mislabelling during upload of the sequence. As no topological variation occurs, the sequence has been retained in the final test.

The placement of the green alga indicates that it belongs to the order Ulvales of the class Ulvophyceae, closely related and basal, on a long branch, in a clade constructed of Pirula salina sequences and the C. emersonii, and four uncultured eukaryotes $(80 / 100)$, obtained from shallow fractures in ultramafic rocks (Daae et al., 2013). This clade appears to be closely related to Dilabifilum and Bildingia clades. Many of the Dilabifilum taxa sampled here which make up this sister clade form lichens (Thüs et al., 2011).

\section{DISCUSSIDN}

Significantly, from this study, we were able to isolate a novel species of Acremonium:

SYSTEMATICS

Order HYPOCREALES Lindau 1897

Family HYPOCREACEAE De Notaris 1844 


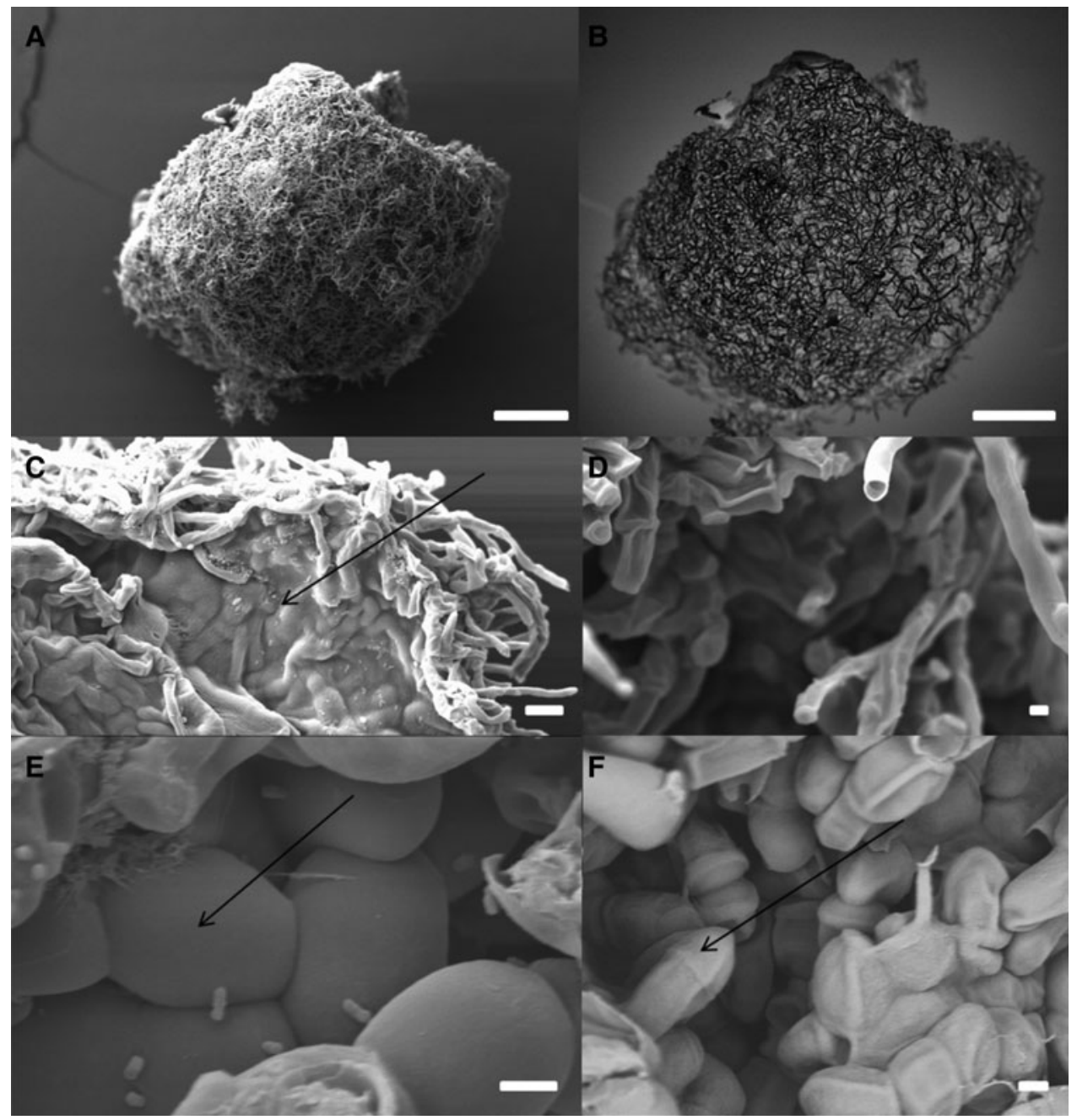

Fig. 4. Scanning electron microscopy of the thallus (i.e. Figure 2). (A) The whole thallus. (B) The same thallus through backscatter. (C) A compact mass of mycelia (arrow). (D) Mycelia in more detail. (E) Smooth, tightly packed, coccoid algal cells (arrow). (F) Mycelia associated, possibly moribund, algal cells. C-F produced by slicing the thallus before fixation. Scale bars A-B, $200 \mu \mathrm{m} ; \mathrm{C}, 10 \mu \mathrm{m} ; \mathrm{D}-\mathrm{F}, 2 \mu \mathrm{m}$

Genus ACREMONIUM Link 1809

\section{Acremonium stroudii K. Fletcher, F.C. Küpper \& P. van} West sp. nov.

Etymology. Named after the collector (Stedson Stroud) of the initial field material.

Habitat. Isolated from environmental sample taken from a seawater blow hole, Whale Point, Ascension Island.

Mycobank Type Strain - CBS 138820

Successful growth on PDA and $\mathrm{OA} 15-24^{\circ} \mathrm{C}$, initially hyphae are white and cottony but eventually flatten. Older parts of fungal growth begin to turn grey-black and underneath of plate is often seen to be so. Central areas of the fungus are often raised. Light levels did not affect the growth of the fungus on plates. Hyphae appear hyaline but not apparently septate under LM. Hyphal diameter typically less than $1 \mu \mathrm{m}$. Conidia when visible seen to be spherical to oblong $1.2-2.0 \mu \mathrm{m}$ in diameter on the periphery of mycelia growth, though larger (up to $3.0 \mu \mathrm{m}$ ) in older parts of the fungus. Germination of conidia not observed.

This novel species is confirmed in its distinctness by the ITS region, which has a $94 \%$ identity to $A$. charticola, the closest taxon on the phylogenetic tree, suggesting a sufficient difference between species. The sequence obtained is placed between two clades containing $A$. charticola labelled sequences which cluster with multiple uncultured clonal sequences and has therefore been included in a monophyletic clade containing A. charticola and A. stroudii only.

A separate finding from this study is the acquisition of a sequence of a novel member of the Ulvales. Distantly related from other Ulvales currently sampled at the SSU $r R N A$ marker, this sequence, closer related to the little-studied $P$. salina and clones taken isolated from ultra-mafic rock (Daae et al., 2013) indicates that the alga branches in a section of the tree currently under-sampled phylogenetically. Though it is commonplace to characterize a photobiont of a symbiosis molecularly without removing the symbiont from the relationship (Thüs et al., 2011), morphologically defining the photobiont in this way is unreliable as the mycobiont may have a significant impact on the algal morphology (Grube \& Muggia, 2010). Given the phylogenetic tree (Figure 7) produced here, it is not possible to place this alga into a currently established genus. Indeed there is a strong indication that this alga belongs to a novel genus, however the inability to isolate this alga, in a pure unialgal, unieukaryotic culture away from fungal contaminants means that it is not possible to describe this species at the 


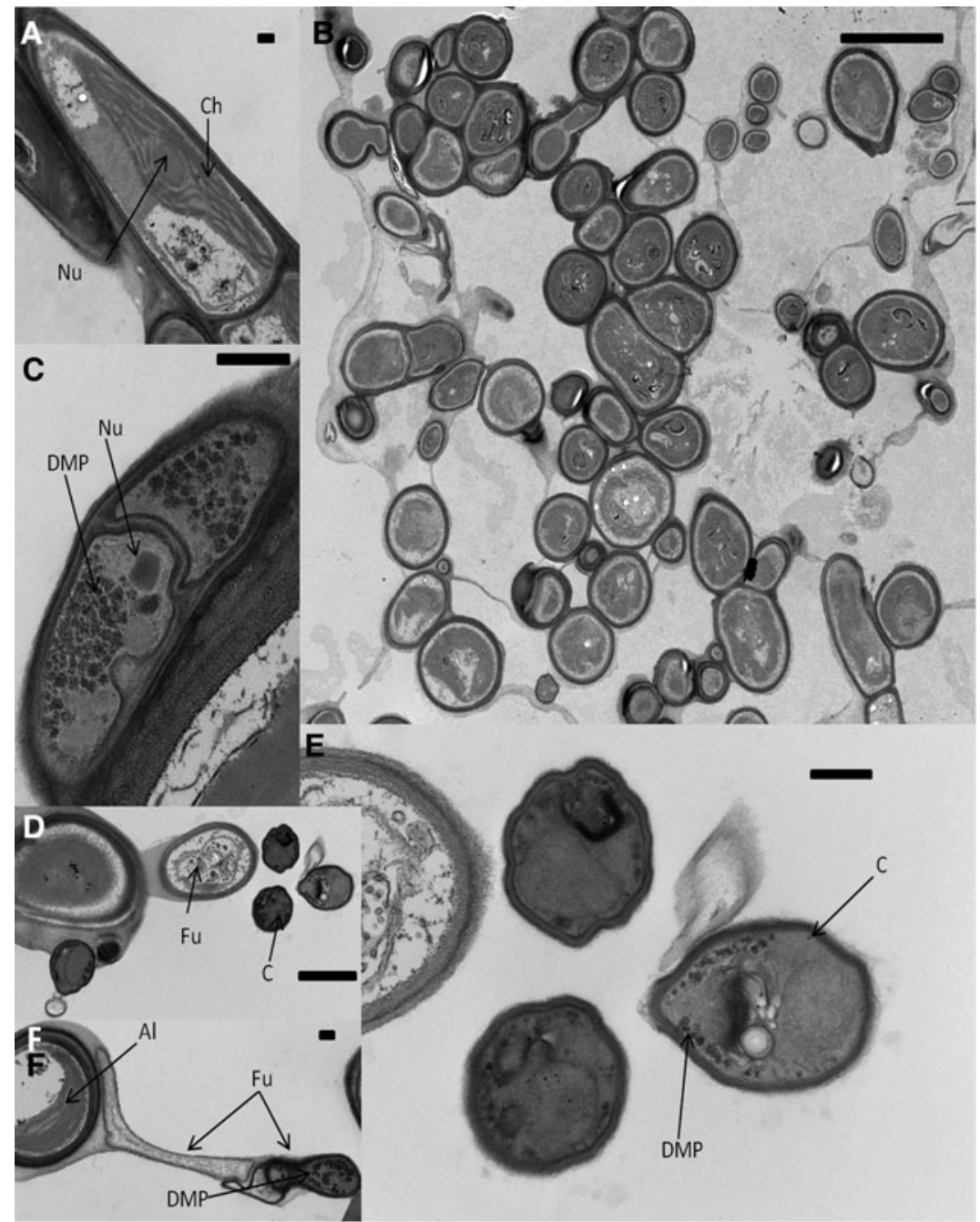

Fig. 5. Transmission electron microscopy of a thallus (i.e. Figure 2). (A) Algal cells, with chloroplast (Ch) and nucleus (Nu). (B) Multiple unicellular algal cells in close proximity. (C) Fungal mycelia associated with algal cell, showing the nucleus (Nu) and dense particles (DMP). (D) Fungal cell (Fu) with conidia (C), (E) higher magnification of conidia (C) with similar dense particles (DMP). (F) Fungal cells (Fu), presenting similar dense particles (DMP) extending towards an algal cell (Al). Scale bars: A, C, E \& F, $500 \mathrm{~nm} ; \mathrm{B}, 10 \mu \mathrm{m} ; \mathrm{D}, 2 \mu \mathrm{m}$.

current time and would therefore not be possible to provide a holotype species for any newly erected genus.

In liquid culture, the alga can been seen to initially grow, free of any contaminating fungi (Figure $2 \mathrm{~A}, \mathrm{C}-\mathrm{F}$ ), though eventually a fungus becomes established and incorporates the algal material within its mycelia (Figure $2 \mathrm{H}$ ). Initially the alga appears as single rounded cells, which develop to form a central cluster of multiple cells (Figure 2A). Subsequently the cluster of cells tends to produce thin elongated cells, which clearly protrude out-width of the cluster (Figure $2 \mathrm{C}-\mathrm{F}$ ). Consistently it was observed that these elongated cells would be seen to be longer and thinner than the central coccoid alga cells. Additionally algal cells would be fewer/slower growing in freshwater BBM (Figure $2 \mathrm{~A}-\mathrm{D}, \mathrm{G}$ ) when compared with those grown in PES (Figure $2 \mathrm{E}-\mathrm{F}$ ). Indeed growth in PES often resulted in a core consisting of such a high density of alga cells, that it would not be possible to clearly distinguish individual cells. The reason for this morphological diversity apparently based on media composition is unknown. Often mycelia could be seen to have originated from circular algal cells (Figure $2 \mathrm{G}$ ) and these could clearly be distinguished from the elongated algal cells, protruding from the core of algal material. There was only a single instance of uncertainty (Figure $2 \mathrm{~B}$ ) where it could not be said with absolute confidence what the origin of the protruding filament was, though given the slight green colouring, early stage of alga growth and relatively thick appearance of the cell it is most likely of algal origin. Between $1-2$ weeks most large algal clusters would become incorporated within a mycelial mat (Figure $2 \mathrm{H}$ ), while smaller algal colonies would remain independent, however eventually all algal colonies would become a part of this mycelial mat. The alga continued to grow at a lower rate once incorporated within this mat and eventually protruding cells seemed to diminish, often filaments of coccoid cells could instead be seen protruding from algal colonies incorporated in mycelial mats for an extended period of time ( $>_{1}$ month). As far as this study could tell it appears that maintaining the alga within culture associated with mycelia was possible when the alga was maintained in liquid PES or $\mathrm{BBM}$ at $20^{\circ} \mathrm{C}$, lower temperature 


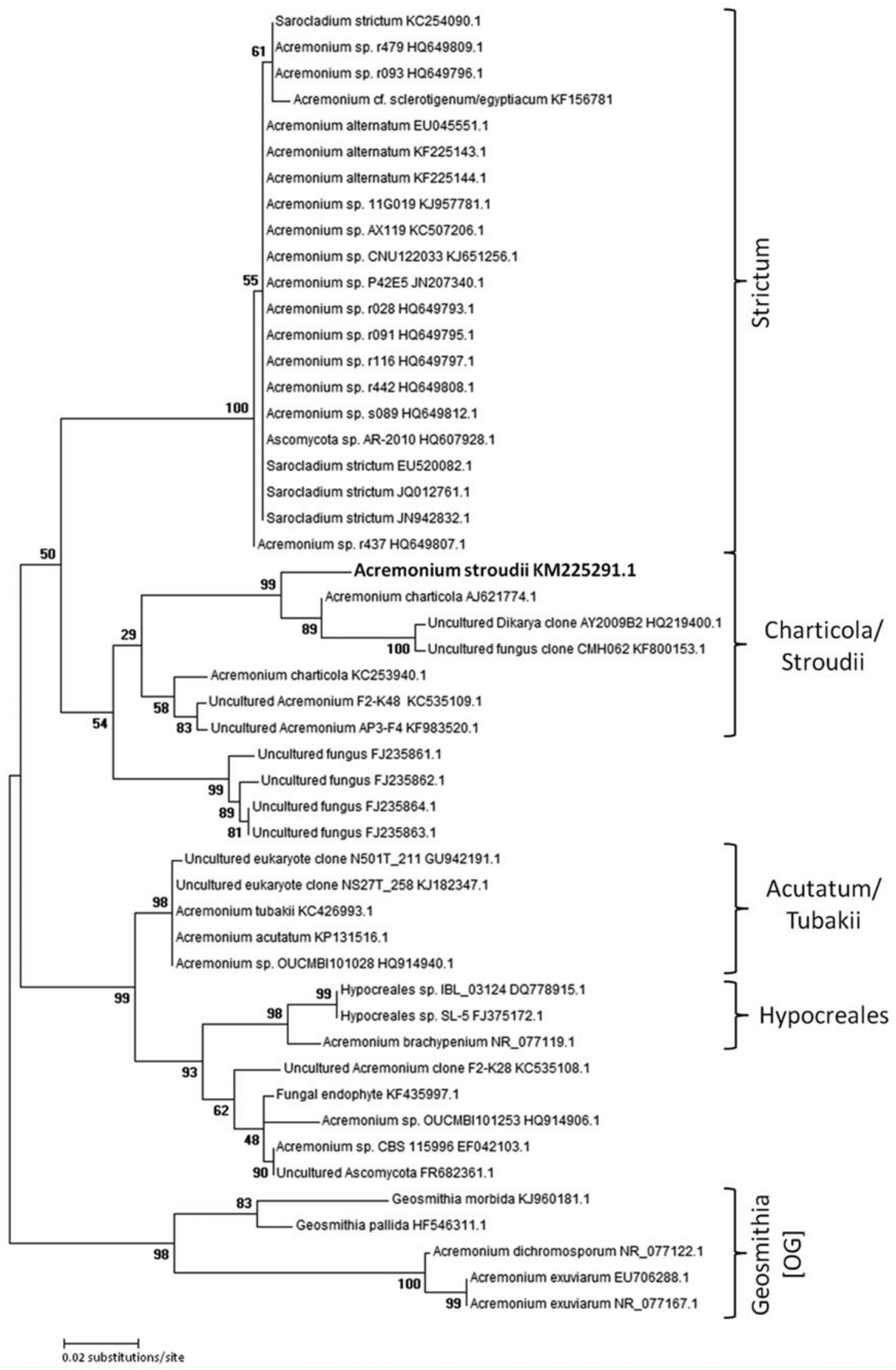

Fig. 6. Maximum likelihood topology of a surveyed section of the genus Acremonium (Ascomycota) at the ITS marker, with 1000 bootstraps as a test of phylogeny, with branches marked with bootstrap scores out of 100 . The sequence of A. stroudii obtained in this study can be seen in bold. 


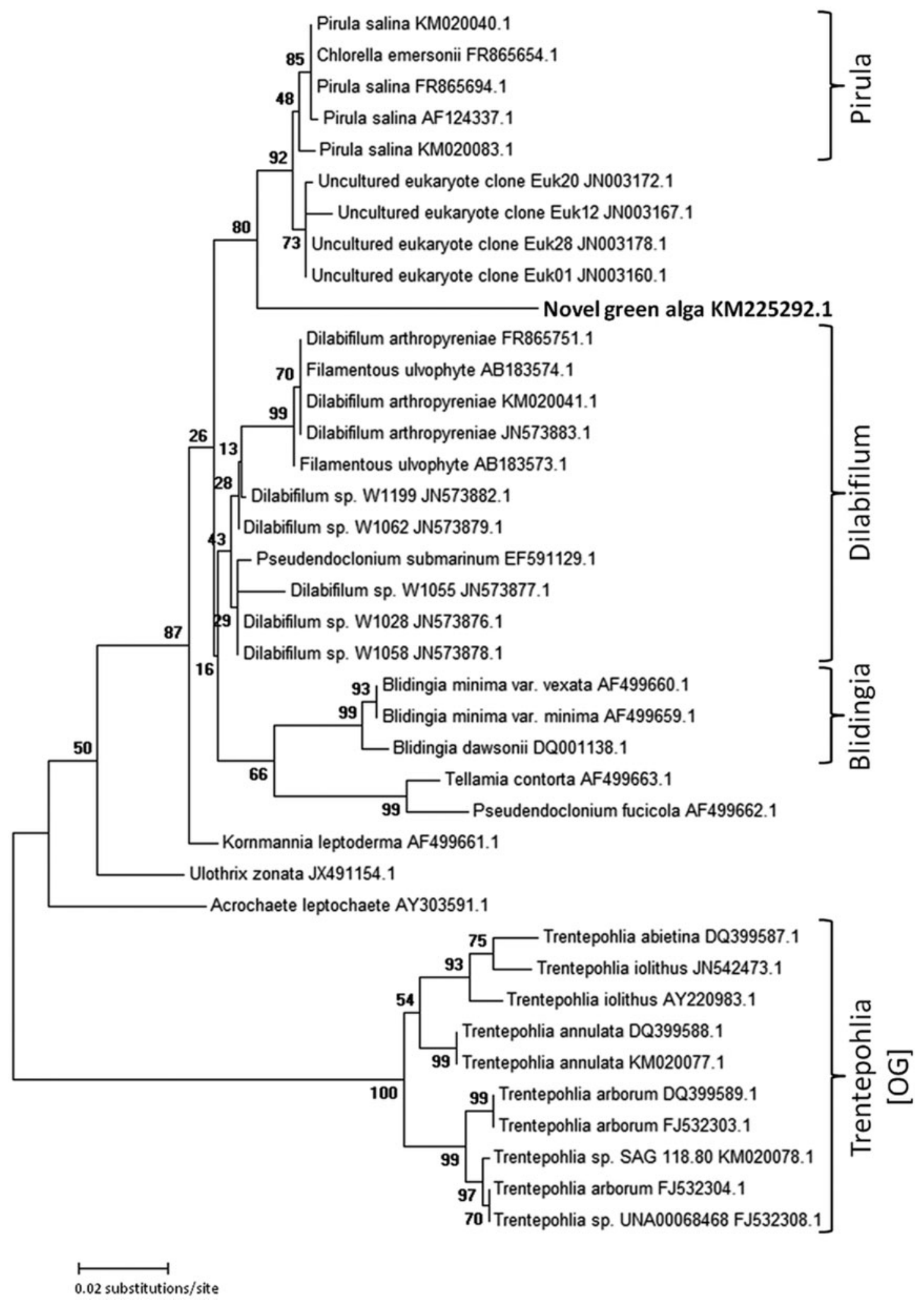

Fig. 7. A maximum likelihood topology exploring the relationships of Pirula species and environmental sequences that clade with these, against Dilabifilum and Blidingia clades. Trentepohlia species are used to root the tree. 1000 bootstraps were used as a test of phylogeny. Branches are marked with bootstrap scores out of 100. The green alga environmental sequence obtained in this study can be seen in bold.

resulted in the eventual decline of the alga. In contrast, when on solid BBM agar plates the alga is seen to be entirely encased in fungal mycelia (Figures $3-5$ ). The material is apparently segregated so that alga cells make up the majority of the internal mass, while fungal mycelia are seen on the outside (Figure 3). While TEM failed to reveal any suggestion of the invasion of algal cells by associated fungal mycelia, SEM did indicate that morphological changes are presented by 
the alga when in close contact with a fungus (Figure 4). Unfortunately no comparison with axenic material can be made at this point.

The mixed culture specimen has been passed through several generations of culture in the manner described here (mechanical disruption of material followed by dilution establishment of solid or liquid cultures), however we are yet to investigate if it would be possible to alter/select the fungal symbiont, i.e. using other known algal symbiotic fungi, to establish an interaction with our algal specimen here or if such an alteration has an effect on the algal morphology. Possible untested hypotheses for the failure to culture this organism away from the fungus could be that the alga requires something from the fungus, to allow it to grow. Another possibility may be that the alga is adapted to fungal cultivation, in that it is used to this form of exploitation and has no defences against it.

It is possible that other free-living members of this potential genus will exist on Ascension Island. We would therefore recommend that future surveys should be carried out looking not only at green algae, but also the green algal symbionts of current lichens on the island, such as those defined in previous studies (Aptroot, 2008; Aptroot et al., 2012).

\section{An untapped source of algal biodiversity?}

This new photobiont sequence, supported by the relatively close clading of four different $18 \mathrm{~S}$ clones (Euk1 Euk12, Euk2o and Euk28) isolated from shallow fractures in ultramafic rocks from Leka Island, Norway (Daae et al., 2013), suggests that there may be a wealth of untapped biodiversity to be discovered in areas such as these (i.e. fissures/blowholes on volcanic islands). Unfortunately the morphology of the Norwegian clones is not known (as no morphological data of the original samples were recorded), yet the acquisition of ascomycete sequences as well as these green algal sequences may hint towards lichen formation. This theory is also supported by the finding in the aforementioned study, as all other algal eukaryotic clones isolated from the shallow fractures form a monophyletic clade of short branches with Trebouxia usneae (a lichen-forming green alga; Hildreth \& Ahmadjian, 1981; Kroken \& Taylor, 2000) and one clone as a basal branch to the clade (Daae et al., 2013). Therefore it could be seen that all those clones discovered in the aforementioned study form two monophyletic clades closely related to lichen-forming green algae (i.e. Dilabifilum and Trebouxia). We would therefore suggest that these are two areas of the green algal phylogeny that may have been molecularly undersurveyed thus far. Investigating green algae, which form an assumed symbiosis with fungi may therefore be a fruitful area for further investigation, especially algae occurring in remote and under-sampled geographic locations.

In conclusion, we have described one novel fungal taxon found from an environmental sample, taken from seawater blow holes of Whale Point, Ascension Island. Alongside this a new lineage of algae has been identified, though at present left undescribed. The sole member of this lineage is an alga which comes from the same environmental sample and appears to readily and hastily become encased in a thallus of fungal mycelia while on solid media and appears to encourage fungal growth in liquid culture, apparently without detriment to the alga. The mechanism of how this is accomplished remains unexplored, as does the diversity of fungi which can form this relationship. It is also unclear as to whether the relationship formed between the alga under investigation here and the fungus is a lichenized symbiosis, as no mature thalli were observed. Being the sole member of this lineage it should also be of interest to the relevant communities to carry out further surveys of Ascension Island investigating the filamentous green algal populations, to see if fungal free forms of this species or any sister species exist in nature. At the current time, the question whether this lineage of green algae is endemic to Ascension Island has to remain open. The sampling of lichen photobionts of the island should also be seen as key to unlocking more information about possible members of this lineage of green algae. Finally due to the findings of Daae et al. (2013) where clones of environmental samples were closely related to the proposed novel lineage here, it seems that a possible trend may be that recent volcanic islands hold a wealth of algal biodiversity yet to be explored.

\section{ACKNOWLEDGEMENTS}

We would like to thank Alan Orange, Holger Thüs and Akira Peters for providing input on this study through personal communication on the topics of lichen biodiversity and identification. We are also grateful to Akira Peters and Holger Thüs for helpful discussions on isolation of algae, specifically establishing cultures from previously lichenized material. Additionally we thank the University of Aberdeen Microscopy and Histology Core Facility for providing specialist electron microscopy support for preparation and imaging of specimens. We are grateful to the Shallow Marine Surveys Group and the South Atlantic Environmental Research Institute for organizing the expedition. We are also very grateful to the Ascension Island Government, the members of staff at the Conservation Centre and Ascension Island Dive Club for their cooperation, accommodation and hospitality. Finally we are grateful to British Forces South Atlantic Islands for their logistic support.

\section{FINANCIAL SUPPORT}

This work was supported by the National Environmental Research Council (K.I.G.F., P.v.W.), Marine Alliance for Science and Technology for Scotland (F.C.K., grant number HRo9011), the University of Aberdeen, Biotechnology and Biological Sciences Research Council (P.v.W.) and the Darwin Initiative (grant number EIDCFo12).

\section{REFERENCES}

Ahmadjian V. (1993) The lichen symbiosis. Waltham, MA: John Wiley \& Sons.

Aptroot A. (2008) Lichens of St Helena and Ascension Island. Botanical Journal of the Linnean Society 158, 147-171.

Aptroot A., Darlow A. and Lambdon P. (2012) Lichens of St Helena. Newbury: Pisces Publications.

Belton T. (2008) Management strategy for Mexican thorn (Prosopis juliflora) on Ascension Island: an assessment of this species, and recommendations for management. Sandy: Royal Society for the Protection of Birds. 
Bischoff H.W. and Bold H.C. (1963) Some soil algae from Enchanted Rock and related algal species. Austin, TX: University of Texas.

Bold H.C. and Wynne M.J. (1985) Introduction to the algae: structure and reproduction. Englewood Cliffs, NJ: Prentice-Hall.

Brown J.C. (1877) Forests and moisture: or effects of forests on humidity of climate. Edinburgh: Oliver and Boyd.

Catling D.C. and Stroud S. (2015) The greening of Green Mountain Ascension Island. In Joachim M. and Silver M. (eds) Post-sustainable: new directions in ecological design. New York, NY: Metropolis Books, in press.

Daae F., Økland I., Dahle H., Jørgensen S., Thorseth I. and Pedersen R. (2013) Microbial life associated with low-temperature alteration of ultramafic rocks in the Leka ophiolite complex. Geobiology 11 $318-339$.

Diederich P. (2003) New species and new records of American lichenicolous fungi. Herzogia 16, 41-90.

Fairhurst W. (2004) Flowering plants of Ascension Island. Alfreton: Higham Press.

Fontaniella B., Molina M.C. and Vicente C. (2000) An improved method for the separation of lichen symbionts. Phyton (Austria) 40, 323-328.

Gachon C.M.M., Strittmatter M., Müller D.G., Kleinteich J. and Küpper F.C. (2009) Detection of differential host susceptibility to the marine oomycete pathogen Eurychasma dicksonii by real-time PCR: not all algae are equal. Applied Environmental Microbiology 75, $322-328$.

Grube M. and Muggia L. (2010) Identifying algal symbionts in lichen symbioses. In Nimis P.L. and Vignes Lebber R. (eds) Tools for Identifying Biodiversity: Progression and Problems. Proceedings of the International Congress, Paris, September 20-22, 2010, pp. 295-299.

Hall T.A. (1999) BioEdit: a user-friendly biological sequence alignment editor and analysis program for Windows 95/98/NT. Nucleic Acids Symposium Series 41, 95-98.

Hildreth K. and Ahmadjian V. (1981) A study of Trebouxia and Pseudotrebouxia isolates from different lichens. The Lichenologist 13, 65-86.

Ichimura T. (1973) The life cycle and its control in some species of Closterium, with special reference to the biological species problems. D Sci thesis. University of Tokyo, Japan.

Kohlmeyer J.A.N. and Kohlmeyer E. (1972) Is Ascophyllum nodosum lichenized? Botanica Marina 15, 109.

Kroken S. and Taylor J.W. (2000) Phylogenetic species, reproductive mode, and specificity of the green alga Trebouxia forming lichens with the fungal genus Letharia. The Bryologist 103, 645-66o.
Lawrey J.D. and Diederich P. (2003) Lichenicolous fungi: interactions, evolution, and biodiversity. The Bryologist 106, 80-120.

McCarthy M. and George A.S. (2002) His Majesty's Ship Roebuck (16901701). Western Australian Maritime Museum. Department of Maritime Archeology No. 159.

Mundy P., Temple R.C. and Anstey L.M. (1907) The travels of Peter Mundy in Europe and Asia, 1608-1667. Cambridge: Hakluyt Society.

Perdomo H., Sutton D., García D., Fothergill A., Cano J., Gené J., Summerbell R., Rinaldi M. and Guarro J. (2011) Spectrum of clinically relevant Acremonium species in the United States. Journal of Clinical Microbiology 49, 243-256.

Provasoli L. (1968) Media and prospects for the cultivation of marine algae. In Cultures and Collections of Algae. Proceedings of the US-Japan Conference, Hakone, September 1966. Japanese Society for Plant Physiology, pp. 63-75.

Starr R.C. and Zeikus J.A. (1993) UTEX - the culture collection of algae at the University of Texas at Austin 1993 list of cultures. Journal of Phycology 29, 1-106.

Summerbell R., Gueidan C., Schroers H., De Hoog G., Starink M. Rosete Y.A., Guarro J. and Scott J. (2011) Acremonium phylogenetic overview and revision of Gliomastix, Sarocladium, and Trichothecium. Studies in Mycology 68, 139-162.

Tamura K., Stecher G., Peterson D., Filipski A. and Kumar S. (2013) MEGA6: molecular evolutionary genetics analysis version 6.0. Molecular Biology and Evolution 30, 2725-2729.

Thüs H., Muggia L., Pérez-Ortega S., Favero-Longo S.E., Joneson S., O’Brien H., Nelsen M.P., Duque-Thüs R., Grube M. and Friedl T. (2011) Revisiting photobiont diversity in the lichen family Verrucariaceae (Ascomycota). European Journal of Phycology 46 , $399-415$.

and

White T.J., Bruns T., Lee S. and Taylor J. (1990) Amplification and direct sequencing of fungal ribosomal RNA genes for phylogenetics. PCR Protocols: A Guide to Methods and Applications 18, 315-322.

\section{Correspondence should be addressed to:}

P. van West

Aberdeen Oomycete Laboratory, Institute of Medical Sciences University of Aberdeen, Foresterhill, Aberdeen AB25 2ZD Scotland, UK email: p.vanwest@abdn.ac.uk 